\title{
KONDISI USAHA PERIKANAN TANGKAP PASCA GEMPA DI SUMATERA BARAT
}

\author{
Eni Kamal \\ Fakultas Ekonomi Universitas Bung Hatta \\ Jalan Sumatra Ulak Karang, Padang, Sumatra Barat, Indonesia, 25133
}

Diterima 20 Januari 2011/Disetujui 8 Mei 2011

\begin{abstract}
Earthquake that occurred in the area of West Sumatera, especially the earthquake that occurred repeatedly since 2004 to 2009 has greatly impacted to the progress and development of fishing effort in seven districts that have sea area in West Sumatera. This study aims to assess the marine business conditions after the earthquake in West Sumatra for can be considered to make policy in the management of fishing effort further. Marine fisheries statistics data indicate that there has been a decline in the number of fishermen postearthquake from 2005 to 2009 as 22.49 percent, the decline in capture fisheries production to 16.12 percent and a decrease in the fishing fleet to 23.89 percent. In resource management and development strategies in the field of maritime affairs and fisheries, it is important to make a comprehensive policy after the earthquake in West Sumatra.
\end{abstract}

Keywords: management fishing effort, marine business, empowerment of coastal, over fishing

\begin{abstract}
Abstrak: Gempa yang terjadi di kawasan Sumatera Barat, terutama gempa yang berulangkali terjadi sejak tahun 2004 hingga tahun 2009 sangat berdampak bagi kemajuan dan perkembangan usaha perikanan tangkap pada tujuh/kota yang mempunyai wilayah laut di Sumatera Barat. Penelitian ini bertujuan untuk mengkaji kondisi usaha kelautan pasca gempa di Sumatera Barat agar dapat dijadikan pertimbangan untuk membuat kebijakan dalam pengelolaan usaha perikanan selanjutnya. Data statistik perikanan dan kelautan menunjukkan bahwa telah terjadi penurunan jumlah nelayan setelah pasca gempa dari tahun 2005 ke 2009 sebesar 22,49 persen, penurunan produksi usaha perikanan tangkap sebesar 16,12 persen dan penururunan armada penangkapan ikan sebanyak 23,89 persen. Penurunan ini disebabkan oleh ketakutan dari nelayan untuk pergi melaut dan dikhawatirkan akan terjadi gempa susulan yang berpotensi tsunami. Dalam pengelolaan sumber daya dan strategi pembangunan pada bidang kelautan dan perikanan, sangatlah penting untuk dibuat kebijakan yang menyeluruh pasca gempa di Sumatera Barat.
\end{abstract}

Kata kunci: manajemen perikanan tangkap, bisnis kelautan, pemberdayaan pesisir, over fishing

\section{PENDAHULUAN}

Posisi Sumatera Barat yang terletak di pantai barat Sumatera yang berhubungan langsung dengan Samudera Hindia mempunyai luas perairan laut lebih kurang $138.750 \mathrm{~km}^{2}$ dan ini belum termasuk perairan Zona Ekonomi Ekslusif Indonesia (ZEEI). Panjang garis pantai kesuluruhannya termasuk Kepulauan Menta- wai adalah $2.045 \mathrm{~km}$ dengan jumlah pulau 125 buah dan 70 persen tersebar di Kepulauan Mentawai. Dari 19 kabupaten/kota yang ada di Sumatera Barat hanya tujuh yang memiliki wilayah laut yaitu kabupaten Pasaman Barat, kabupaten Agam, kabupaten Padang Pariaman, kota Pariaman, kota Padang, kabupaten Pesisir Selatan dan kabupaten Kepulauan Mentawai.

Kawasan laut dan perikanan tangkap di 
Sumatera Barat memiliki masalah ketimpangan struktural yaitu sudah lama didominasi oleh armada skala kecil. Magnitude-nya bergeser secara perlahan, namun trennya tetap saja sama yaitu skala kecil tetap mayoritas. Secara ilustrasi, pada tahun 1999 nelayan skala kecil di Sumatera Barat mendominasi 82,78 persen dan setelah berselang 5 (lima) tahun (2003) dengan berbagai program dan proyek, seperti program pemberdayaan ekonomi nelayan sedikit menurun menjadi 80 persen, dengan kata lain perubahan struktural tidak terjadi secara signifikan selama lima tahun. Akibat dominasi perikanan skala kecil, kawasan laut dan perikanan tangkap tidak banyak mendatangkan kontribusi bagi peningkatan pendapatan ekonomi pada tujuh kawasan pesisir di Sumatera Barat. Bermula dari terjadinya gempa dan tsunami di Aceh pada bulan Desember 2004, gempa di Bengkulu 2007, dan gempa bulan September 2009 di Sumatera Barat, produktivitas perikanan tangkap menjadi rendah, akhirnya pendapatan rata-rata nelayan penangkap ikan skala kecil (tradisional) semakin terpuruk yang disebabkan oleh faktor alam. Jumlah nelayan, jumlah armada, jumlah trip, dan jumlah produksi ikan tiap tahun menunjukan pertumbuhan ekonomi yang cenderung menurun tiap tahunnya.

Jumlah Nelayan dan Produksi Perikanan Tangkap. Sebelum terjadinya gempa di Sumatera Barat, jumlah nelayan, produksi perikanan tangkap, jumlah armada penangkapan, dan jenis alat tangkap menunjukkan peningkatan tiap tahunnya seperti pada Tabel 1-Tabel 5.

Tabel 1 menunjukkan bahwa telah terjadi penurunan jumlah nelayan yang signifikan sejak tahun 2004 dibandingkan dengan tahun 2009. Pada tahun 2004 jumlah nelayan 32.232 orang (nelayan tetap 24.180 dan sambilan 8.052 orang), sedangkan pada tahun 2009 jumlah nelayan 26.314 orang (21.873 nelayan tetap dan 4.441 nelayan sambilan). Hal ini menunjukkan telah terjadi penurunan nelayan dari tahun 2004 ke tahun 2009 sebesar 22,49 persen. Penurunan jumlah nelayan tertinggi yaitu pada nelayan sambilan sebesar 44,97 persen sedangkan pada nelayan tetap sebesar 9,50 persen.

Penurunan jumlah nelayan umumnya terjadi pada kabupaten/kota yang mempunyai wilayah laut. Penurunan jumlah nelayan ini diduga disebabkan oleh kejadian gempa, karena pada rentang tahun 2004 sampai 2009 sering terjadi kejadian gempa, terutama gempa yang berskala di bawah 5 SR dan ditambah dengan adanya isu-isu yang berkembang di tengah masyarakat pesisir tentang isu potensi tsunami dan membuat masyarakat pesisir trauma untuk melaut. Sebagian besar nelayan telah mengalihkan mata pencahariannya ke sektor lain. Nelayan tetap sebanyak 32,45 persen mengalihkan mata pencahariannya ke sektor perkebunan dan pertanian terutama di kabupaten Pasaman Barat, Agam dan Pesisir Selatan dan 24,27 persen ke sektor jasa (sopir, agen, tukang ojek) yaitu di kota padang, pariaman, dan 12,17 persen ke sektor perdagangan (membuka warung nasi

Tabel 1. Jumlah Nelayan Tetap dan Nelayan Sambilan (Orang) di Sumatera Barat dari Tahun 1998-2009

\begin{tabular}{cccc}
\hline $\begin{array}{c}\text { Sumatera barat } \\
\text { Tahun }\end{array}$ & Nelayan tetap & Nelayan sambilan & Jumlah \\
\hline 1998 & 24.106 & 8.575 & 32.681 \\
1999 & 24.283 & 8.052 & 32.335 \\
2000 & 24.373 & 7.994 & 32.367 \\
2001 & 25.843 & 6.549 & 32.392 \\
2002 & 23.258 & 8.389 & 31.647 \\
2003 & 24.169 & 8.052 & 32.221 \\
2004 & 24.180 & 8.052 & 32.232 \\
2005 & 23.769 & 7.072 & 30.841 \\
2006 & 23.009 & 6.239 & 29.248 \\
2007 & 22.819 & 6.004 & 28.823 \\
2008 & 22.432 & 5.096 & 27.528 \\
2009 & 21.873 & 4.441 & 26.314 \\
\hline
\end{tabular}

Sumber: diolah dari data statistik perikanan Sumatera Barat (Tahun 1998-2009) 
dan warung lainnya). Sedangkan untuk nelayan sambilan, sebanyak 56,20 persen mengalihkan mata pencariannya menjadi tukang ojek dan sisanya jasa lainnya.

Dengan terjadinya penurunan jumlah nelayan, tentu akan berpengaruh pada jumlah produksi, karena hal ini berarti telah berkurangnya proses aktivitas baik dari jumlah tangkapan maupun dari jumlah trip nelayan. Pada Tabel 2 menunjukkan sejak terjadinya gempa di akhir tahun 2004, jumlah produksi perikanan tangkap telah terjadi penurunan. Produksi perikanan tangkap pada tahun 2004 adalah 102.368 ton. Kalau dibandingkan dengan produksi tahun 2009 sebesar 85.861,60 ton maka telah terjadi penurunan produksi sebesar 16,12 persen.

Tabel 2. Produksi Perikanan Tangkap (ton) di Sumatera Barat dari Tahun 1998-2009.

\begin{tabular}{cc}
\hline Sumatera barat & Produksi \\
\hline 1998 & $91.187,30$ \\
1999 & $91.400,70$ \\
2000 & $94.274,40$ \\
2001 & $87.543,20$ \\
2002 & $85.745,00$ \\
2003 & $98.047,10$ \\
2004 & $102.368,00$ \\
2005 & $98.912,70$ \\
2006 & $96.090,00$ \\
2007 & $89.088,80$ \\
2008 & $87.043,00$ \\
2009 & $85.861,60$ \\
\hline
\end{tabular}

Sumber: diolah dari data statistik perikanan Sumatera Barat (Tahun 1998-2009)
Dari Tabel 2 juga terlihat dengan jelas sejak pasca gempa tahun 2005 sampai tahun 2009, penurunan produksi tiap tahunnya selalu terjadi, seperti pada tahun 2006 jumlah produksi adalah 96.090 ton dan begitu seterusnya. Dengan terjadinya penurunan produksi ikan di Sumatera Barat maka berimbas pada kurangnya pasokan ikan ke pasar-pasar tradisional dan di sekitar ibu kota kabupaten/kota, sehingga harga ikan di tingkat pasar mengalami kenaikan. Untuk memasok kekurangan ini, ternyata lebih dari 20,00 persen didatangkan dari provinsi tetangga seperti Sibolga dan Bengkulu, sedangkan penjualan ikan keluar daerah dari Sumatera Barat ke provinsi Riau dan Jambi terjadi penurunan sebesar 18,50 persen (DKP, 2010).

Seiring dengan terjadinya penurunan nelayan yang cukup signifikan, ternyata disebabkan juga karena penurunan armada penangkapan ikan. Sebagian besar armada penangkapan ikan pasca gempa banyak tidak melaut dan sebagian besar juga banyak tidak diperbaiki setelah rusak dan sebagian lainnya dijual ke daerah lainnya, seperti ke provinsi tetangga Sumatera Barat (Natal dan Sibolga) dan Bengkulu. Sejak pasca gempa tahun 2005 sampai tahun 2009, penurunan armada penangkapan adalah sebesar 23,89 persen (Tabel 3) dan penurunan armada yang tertinggi adalah pada klasifikasi perahu motor yang kebanyakan masih digunakan oleh nelayan yang jarak operasionalnya 4 mil atau disebut juga masih tradisional.

Dari klasifikasi alat tangkap di Sumatera

Tabel 3. Jumlah dan Klasifikasi Armada Penangkapan Ikan (Unit) di Sumatera Barat dari Tahun 1998-2009.

\begin{tabular}{ccccc}
\hline Sumatera Barat & Perahu tanpa motor & Motor tempel & Kapal motor & Jumlah \\
\hline 1998 & 5.604 & 1.759 & 1.291 & 8.654 \\
1999 & 5.395 & 1.746 & 1.397 & 8.538 \\
2000 & 5.115 & 1.706 & 1.431 & 8.252 \\
2001 & 5.313 & 1.699 & 1.577 & 8.589 \\
2002 & 4.718 & 1.363 & 1.217 & 7.298 \\
2003 & 4.125 & 2.119 & 1.275 & 7.519 \\
2004 & 5.313 & 1.699 & 1.577 & 8.589 \\
2005 & 4.718 & 1.363 & 1.209 & 7.290 \\
2006 & 4.543 & 1.279 & 1.187 & 7.009 \\
2007 & 4.475 & 1.259 & 1.175 & 6.909 \\
2008 & 4.390 & 1.240 & 1.162 & 6.792 \\
\hline
\end{tabular}

Sumber: diolah dari data statistik perikanan Sumatera Barat (Tahun 1998-2009) 
Barat, umumnya masih berskala tradisional. Jenis yang masuk kategori perahu tanpa motor adalah perahun nelayan tradisional yang jarak tempuhnya sangat terbatas. Dengan adanya program pemberdayaan pesisir dan kelautan yang dicanangkan oleh Departemen Kelautan dan Perikanan sejak tahun 1998 sampai tahun 2007, alat tangkapnya berupa pancing, pukat pantai, jala, dan alat tangkap lainnya sebagain besar sudah diberi mesin ROBIN (long tail) sehinga jarak tempuh agak lebih jauh, tetapi operasionalnya tetap kategori alat tangkap tradisional. Sedangkan klasifikasi motor tempel adalah yang masuk pada jenis alat tangkap payang, dogol, jaring insang hanyut, insang tetap dan kapal motor adalah jenis alat tangkap purse seine, bagan, tonda, mini long line, jaring multifilament lannya.

\section{PEMBAHASAN}

Dengan terjadinya musibah gempa bumi di Sumatera Barat dan sejak gempa tahun 2004 di
Aceh dan Sumatera Barat, membuat masyarakat pesisir terutama nelayan enggan pergi melaut. Jika dilihat dari potensi perikanan dan kelutan, Sumatera Barat mempunyai perairan yang luasnya $186.580 \mathrm{~km}^{2}$ (termasuk ZEE), dengan panjang garis pantai $2.045 \mathrm{~km}$ dan terdiri 19 kabupaten/kota, tujuh di antaranya mempunyai wilayah pesisir. Berdasarkan Komisi Stock Assessment Nasional, potensi sumber daya perikanan Sumatera Barat adalah 340.712 ton/tahun (DKP, 2009). Ini berarti tingkat pemanfaatannya jika dibandingkan dengan hasil tangkapan sebelum gempa tahun 2003 adalah sebesar 30,20 persen dan setelah pasca gempa tahun 2005 sebesar 29,62 persen. Pemanfaatan potensi lestari ini menurun sampai tahun 2009 sebesar 25,20 persen dilihat dari luas potensi perikanan, jumlah nelayan dan alat tangkap ikan dalam mengelola sumber daya perikanan. Dari segi kuantitas, nilai tersebut cukup besar namun dari segi produktifitas dan kualitas masih jauh dari yang diharapkan karena umumnya nelayan di Sumatera Barat masih berupa

Tabel 4. Harga BBM yang Dijual di Kawasan Konsentrasi Nelayan di Sumatera Barat

\begin{tabular}{|c|c|c|c|c|}
\hline Kabupaten/Kota & $\begin{array}{l}\text { Kawasan } \\
\text { Nelayan }\end{array}$ & Solar (Rp./Ltr) & $\begin{array}{c}\text { Bensin } \\
\text { (Rp./Ltr) }\end{array}$ & $\begin{array}{c}\text { Minyak Tanah } \\
\text { (Rp./Ltr) }\end{array}$ \\
\hline \multirow[t]{3}{*}{ Pasaman Barat } & Air Bangis & $4.800-5.100$ & $4.900-5.200$ & $3.250-3.500$ \\
\hline & Sasak & $4.800-5.100$ & $4.900-5.200$ & $3.250-3.500$ \\
\hline & $\begin{array}{l}\text { Mandiangin \& } \\
\text { Katiagan }\end{array}$ & $5.000-5.500$ & $5.100-5.500$ & $3.500-4.000$ \\
\hline \multirow[t]{3}{*}{ Agam } & Masang \& & $5.000-5.500$ & $5.100-5.500$ & $3.500-4.000$ \\
\hline & Muara Putus & & & \\
\hline & $\begin{array}{l}\text { Tiku@ Gasan } \\
\text { Ketek }\end{array}$ & $4.800-5.100$ & $4.700-5.100$ & $3.250-3.500$ \\
\hline Padang Pariaman & $\begin{array}{l}\text { Pasir Baru, Sie. } \\
\text { Limau }\end{array}$ & $4.800-5.100$ & $4.700-5.100$ & $3.250-3.500$ \\
\hline Kota Pariaman & Naras dan Kota & $4.600-4.800$ & $4.600-4.800$ & $3.000-3.250$ \\
\hline \multirow[t]{4}{*}{ Kota Padang } & Pasir Sebelah & $4.600-4.800$ & $4.700-4.800$ & $2.800-3.150$ \\
\hline & Ulak Karang & $4.500-4.600$ & $4.700-4.800$ & $2.800-3.150$ \\
\hline & Purus, Muara & $4.500-4.700$ & $4.700-4.800$ & $2.800-3.000$ \\
\hline & Bungus & $4.500-4.700$ & $4.700-4.800$ & $2.900-3.000$ \\
\hline \multirow[t]{2}{*}{ Pesisir Selatan } & $\begin{array}{l}\text { Tarusan, } \\
\text { Carocok }\end{array}$ & $4.400-4.600$ & $4.600-4.800$ & $3.000-3.250$ \\
\hline & Painan Kota & $4.400-4.600$ & $4.600-4.800$ & $3.000-3.250$ \\
\hline \multirow[t]{3}{*}{ Kep. Mentawai } & Sikakap & $6.400-6.500$ & $6.600-6.800$ & $4.600-5.000$ \\
\hline & Sipora & $6.200-6.300$ & $6.500-6.800$ & $4.500-4.800$ \\
\hline & Siberut & $6.2000-6.500$ & $6.600-6.800$ & $4.500-5.500$ \\
\hline
\end{tabular}

Sumber: diolah dari pantauan lapangan dan informasi nelayan, November 2009 
usaha yang turun temurun dari satu generasi ke generasi berikutnya.

Selain dari adanya fenomena alam yaitu gempa, faktor lainnya adalah kebijakan pemerintah yang menaikkan harga BBM di tahun 2005. Hal tersebut sudah jelas sangat merugikan nelayan di Sumatera Barat secara langsung, karena tingginya biaya produksi yang harus dikeluarkan dalam membeli BBM. Tabel 4 menunjukkan harga BBM yang riil dibeli nelayan di sentra-sentra nelayan di tujuh kabupaten/kota di Sumatera Barat.

Upaya-upaya yang harus dilakukan oleh pengambil kebijakan untuk memajukan usaha perikanan yang biasa ditekuni oleh nelayan di Sumatera Barat pasca gempa adalah dengan memprioritaskan pengembangan budidaya pantai, seperti jaring apung, tambak bandeng dan kolam, serta pemanfaatan sungai sebagai ikan larangan. Sumber daya pesisir dapat dimanfaatkan secara maksimal terutama memanfaatkan daerah "estuaria", laguna, dan teluk. Pengembangan ikan dengan memanfaatkan dengan sistem Budidaya Inti Rakyat (BIR) dapat dilakukan di sepanjang kawasan potensil dan masing-masing kabupaten/kota mempunyai potensi untuk dikembangkan, seperti di Air Bangis (Pasaman Barat), Bungus, Sungai Pisang (Padang), Tarusan (Pesisir Selatan), dan kavracan Kenı1laı1 Mentawrai dan efisien jika teknologi yang digunakan dapat melakukan penangkapan dengan hasil yang optimal tetapi dengan biaya yang minimal. Syarat ini bisa terpenuhi jika teknologi yang digunakan mempunyai ketepatan yang tinggi. Mulai dari ketepatan dalam menentukan daerah penangkapan ikan (fishing ground) sampai ketepatan alat tangkap yang akan digunakan.

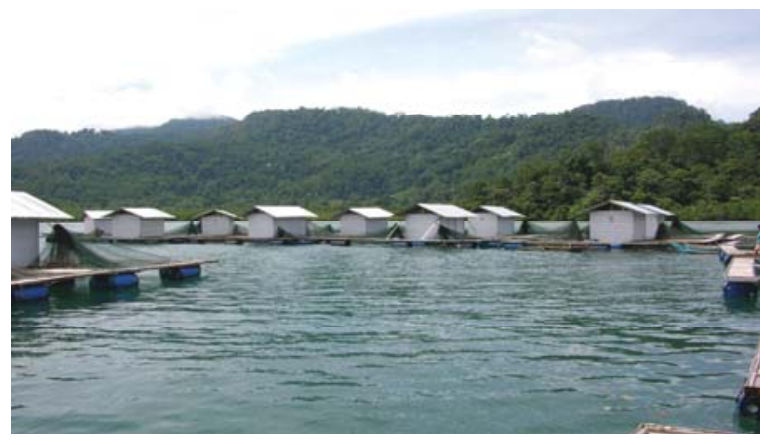

Gambar 1. Contoh Budidaya Pantai yang Dikembangkan di Kawasan Carocok, Kabupaten Pesisir Selatan

Selain menurunnya hasil tangkapan ikan nelayan, kejadian fenomena alam juga berdamspak pada kerusakan ekosistem pesisir, seperti kerısakan hıtan haka11 (manoroz)e) dan ata11 
kan habitat, nursery ground, feeding ground, spawning ground bagi fauna diperairan. Oleh karena itu ekosistem mangrove merupakan lumbung benih kehidupan di laut.

Hutan mangrove suatu ekosistem yang unik dan mempunyai 3 (tiga) fungsi pokok yakni: (1) Fungsi fisik, menjaga garis pantai agar tetap stabil, melindungi pantai dari gempuran ombak dan abrasi, menjadi wilayah penyangga terhadap rembesan air laut (intrusi) dan sebagai filter pencemaran yang masuk ke laut; (2) Fungsi biologis, sebagai daerah asuhan dan tempat pemijahan (nursery ground dan spawning ground) bagi ikan, udang, kepiting, kerang dan biota perairan lainnya (nursery ground), tempat persinggahan burung-burung yang bermigrasi serta tempat habitat alami berbagai jenis biota flora (anggrek) dan fauna lainnya; (3) Fungsi ekonomis, sebagai sumber bahan bakar (arang dan kayu bakar), bahan bangunan (balok, atap rumah dan tikar), perikanan, pertanian, tekstil (serat sintetis), makanan, obat-obatan, minuman (alkohol), bahan mentah kertas, bahan pembuat kapal (gading-gading) dan lainnya. Kerusakan dan terganggunya ekosistem bakau di sepanjang pesisir Sumatera Barat pasca gempa tahun 2004 sampai 2009 yang menyebabkan terjadinya penurunan hasil tangkapan ikan dan biota lainnya dan sudah mulai dirasakan bahkan pada tingkat perairan pantai sudah over fishing, hal ini salah satunya disebabkan oleh rusaknya hutan mangrove, seperti terlihat pada Tabel 5.

Pada tingkat eksploitasi, terlihat jelas bahwa Sumatera Barat telah kehilangan produksi ikan sebesar 8.350 ton/tahun atau 8.320.000 $\mathrm{kg} /$ tahun dan ini sama dengan hilangnya pendapatan masyarakat pesisir sebesar:

Rp41.600.000.000,00. Hal ini menunjukkan bahwa kerusakan ekosistem bakau sangat berhubungan sekali dengan perikanan dengan arti kata rusaknya hutan bakau akan menyebabkan kepunahan pada fauna akuatik karena tidak tersedianya makanan lagi pada perairan yang terdapat pada hutan mangrove. Untuk perbandingan hubungan antara hutan mangrove dengan produksi tangkapan udang dan ikan dari berbagai penelitian dapat dilihat pada Tabel 6.
Tabel 5. Lokasi, Luas, Tingkat Kerusakan Hutan Mangrove dan Prediksi Penurunan Hasil Tangkapan Ikan di Sumatera Barat (Tahun 2004-2009)

\begin{tabular}{lccc}
\hline $\begin{array}{l}\text { Daerah } \\
\text { Lokasi }\end{array}$ & $\begin{array}{c}\text { Luas } \\
\mathbf{( H a )}\end{array}$ & $\begin{array}{c}\text { Tingkat } \\
\text { Kerusakan } \\
\mathbf{( \% )}\end{array}$ & $\begin{array}{c}\text { Prediksi } \\
\text { Kurang Hasil } \\
\text { Tangkapan } \\
\text { (ton/th) }\end{array}$ \\
\hline $\begin{array}{l}\text { Kab. } \\
\text { Pasaman } \\
\text { Barat }\end{array}$ & $6.273,50$ & 30 & 975,00 \\
$\begin{array}{l}\text { Kab. } \\
\text { Pesisir }\end{array}$ & 325,00 & 70 & 227,50 \\
$\begin{array}{l}\text { Selatan } \\
\text { Kab. Pdg } \\
\text { Pariaman }\end{array}$ & 200,00 & 80 & 160,00 \\
$\begin{array}{l}\text { Kab. Kep. } \\
\text { Mentawai }\end{array}$ & $32.600,00$ & 20 & $6.846,00$ \\
$\begin{array}{l}\text { Kab. } \\
\text { Agam }\end{array}$ & 313,50 & 50 & 27,50 \\
$\begin{array}{l}\text { Kota } \\
\text { Pariaman }\end{array}$ & 97,50 & 40 & 39,00 \\
$\begin{array}{l}\text { Kodya } \\
\text { Padang }\end{array}$ & 120,00 & 70 & 84,00 \\
Jumlah & $39.929,00$ & $\mathbf{2 2 , 6 7}$ & $\mathbf{8 . 3 5 9 , 0 0}$ \\
\hline
\end{tabular}

Sumber: Kamal et.al., 2008

Tabel. 6 Hubungan Hasil Tangkapan Udang dan Ikan terhadap Ketersediaan Hutan Mangrove

\begin{tabular}{llll}
\hline $\begin{array}{l}\text { Lokasi/ } \\
\text { Negara }\end{array}$ & $\begin{array}{l}\text { Hasil } \\
\text { Tangkapan } \\
\text { (Ton) }\end{array}$ & $\begin{array}{l}\text { Luas } \\
\text { mangrove } \\
\text { (Ha/th) }\end{array}$ & $\begin{array}{l}\text { Koefisien } \\
\text { korelasi } \\
\text { (N) }\end{array}$ \\
\hline $\begin{array}{l}\text { Australia } \\
\text { Malaysia }\end{array}$ & $0,2-15$ & $0,1-0,8$ & $0,76(6)$ \\
Teluk & $0-25$ & $0-50$ & $0,74(7)$ \\
Mexico & $10-10.000$ & $1-1.000$ & $0,975(15)$ \\
$\begin{array}{l}\text { Afrika Barat } \\
\text { Samudera }\end{array}$ & $1,6-4,5$ & $1-183$ & - \\
$\begin{array}{l}\text { Hindia } \\
\text { Samudera }\end{array}$ & $1,3-3,10,6$ & $1-183$ & - \\
$\begin{array}{l}\text { Hindia } \\
\text { Jawa }\end{array}$ & 0,48 & $1-100$ & - \\
Philipina & $0-25$ & 1,0 & - \\
\hline
\end{tabular}

Sumber: Duta Rimba/Maret-April/77-178/XXI/1995 dalam Kamal, et.al., 1998 
Produktivitas primer hutan mangrove dari biomas tumbuhan berkisar antara 500-4.000 $\mathrm{gram} / \mathrm{m}^{2} /$ tahun, atau rata-rata $2.000 \mathrm{gram} / \mathrm{m}^{2} /$ tahun. Ini berarti dalam satu tahun saja hutan mangrove yang luasnya satu hektar dapat memproduksi 4 ton detritus yang berasal dari flora mangrove, dan ini berarti kita memasukkan "pakan ikan" 4.000 kg/tahun. Kalaulah harga pakan ikan satu kilogram Rp2000,00 maka kita berarti telah rugi sebesar:

Rp8.000.000,00 tiap satu hektar mangrove. Coba bayangkan kalau kerusakannya 8.320 ha, maka investasi yang harus keluar untuk kerusakan lingkungan adalah sebesar:

Rp 66.560.000.000,00. Detritus ini merupakan sumber makanan bagi ikan, udang, moluska dan biota akuatik lainnya yang hidup di sekitar perairan mangrove (Kamal dan Bujang, 1998: 57-58). Sebagai perbandingan produktivitas primer hutan mangrove, terlihat pada Tabel 7.

Tabel 7. Produktivitas Primer Hutan Mangrove yang Dihasilkan oleh Hutan Mangrove

\begin{tabular}{|c|c|c|}
\hline Lokasi/Negara & $\begin{array}{l}\text { Produktivitas } \\
\text { Primer } \\
\text { (Ton/Ha/Tahun) }\end{array}$ & Sumber \\
\hline Jepang & 95,00 & $\begin{array}{l}\text { Suzuki dan } \\
\text { Tegawa, } 1983\end{array}$ \\
\hline Malaysia & 300,00 & Ong, et.al., 1984 \\
\hline $\begin{array}{l}\text { Indonesia (Uj, } \\
\text { Kulon) }\end{array}$ & 9,41 & $\begin{array}{l}\text { Soemodihardjo, } \\
1992\end{array}$ \\
\hline $\begin{array}{l}\text { Indonesia } \\
\text { (Halmahera) }\end{array}$ & 356,80 & $\begin{array}{l}\text { Komiyama, } \\
\text { et.al,1988 }\end{array}$ \\
\hline $\begin{array}{l}\text { Indonesia } \\
\text { (Riau) }\end{array}$ & 155,00 & Kusmana,1993 \\
\hline $\begin{array}{l}\text { Indonesia } \\
\text { (Kaltim) }\end{array}$ & 599,50 & Syahnan, 1994 \\
\hline $\begin{array}{l}\text { Indonesia } \\
\text { (Painan) }\end{array}$ & 2,90 & Sabri,1997 \\
\hline $\begin{array}{l}\text { Indonesia (Air } \\
\text { Bangis) }\end{array}$ & 90,20 & $\begin{array}{l}\text { Kamal, 1999, } \\
2005\end{array}$ \\
\hline
\end{tabular}

Jika dibandingkan dengan hasil yang didapat dengan mengambil kayu mangrove, dalam satu Ha hanya menghasilkan 5 meter kubik kayu dengan nilai Rp600.000,00/m3 dan ini berarti value yang dihasilkan dalam satu ha adalah hanya Rp3.000.000,00 dan kerusakan Rp24.960.000.000,00 dan ini tidak sebanding dengan kerusakan fisik yang berpengaruh pada lingkungan yang diperkirakan mencpai ratusan miliar rupiah.

\section{Upaya Pemanfaatan dan Pengelolaan Mangrove}

Untuk mencari solusi dalam pemanfaatan hutan mangrove tersebut diperlukan kebijakan yang menyeluruh dalam menetapkan kawasan hutan mangrove, terutama dengan melakukan pengawasan dan menjadikan kawasan hutan mangrove sebagai kawasan hutan lindung pada daerah-daerah penyangga di kawasan pesisir pantai. Sudah saatnya pula dilakukan program penghijauan pantai, seperti regenerasi hutan mangrove atau reboisasi pesisir pantai serta menjadikan kawasan hutan mangrove sebagai paru-paru pantai. Program ini dapat dilakukan atau dilaksanakan dengan melibatkan berbagai instansi seperti Departemen Kehutanan, Pemerintah Daerah, Perguruan Tinggi dan masyarakat setempat. Terumbu karang adalah salah satu komponen penyusun ekosistem laut yang mempunyai fungsi sangat penting, antara lain sebagai tempat hidup bagi populasi ikan, tiram, kerang crustacea, penghasil devisa US $\$ 1.125$ milyar per tahun, penahan ombak yang kokoh dan dapat digunakan sebagai bahan bangunan yang baik (Usher, 1997).

Fungsi Terumbu Karang. Terumbu karang sangat berperan terhadap produktivitas suatu perairan dimana produktivitas primernya berkisar antara 300-5000 gc/ $\mathrm{m}^{2} /$ th (Meadows dan Campbell, 1988) lebih tinggi dari laut terbuka, upwelling, estuaria, hutan mangrove padang lamun dan mampu menampung biomoss hewan yang tinggi antara 490-1.400 kg/ha (Baker \& Kaeoniam, 1986). Rusaknya terumbu karang secara langsung akan memberikan dampak terhadap hasil tangkapan nelayan, jumlah dan jenis ikan. Hal ini disebabkan oleh terumbu karang memiliki fungsi dan peranan yang sangat penting di dalam perairan (Damanhuri, 2003).

Terumbu karang memiliki fungsi sebagai tempat perkembangbiakan ikan, perlindungan dan mencari makan bagi ikan, kerang, udang dan biota lainnya. Selain itu karang juga berfungsi sebagai pelindung pantai dari abrasi dan 
gempuran ombak, menstabilkan keliling pulaupulau dan garis pantai dari kikisan ombak yang sangat kuat. Terumbu karang juga dapat dimanfaatkan sebagai tempat pariwisata bahari dan tempat menangkap ikan bagi para nelayan. Terumbu karang juga dapat dieksploitasi untuk bahan bangunan, cenderamata, bahan obat-
Sumatera Barat dapat dilihat pada Tabel 8.

Kerusakan Terumbu Karang. Kerusakan terumbu karang dapat disebabkan oleh dua faktor yaitu faktor alam dan aktivitas manusia. Faktor alam yang dapat menyebabkan kematian seperti gempa, "tsunami", pemanasan global, blooming organisme laut tertentu (pada pre-

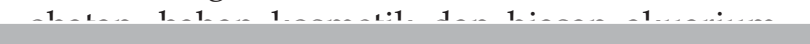

karang di seluruh wilayah laut Indonesia sangat diperlukan. Di perairan Barat Sumatera Barat telah dilakukan penelitian tentang terumbu karang, dari bulan Oktober 2005 sampai akhir 2009. Hasilnya menunjukkan bahwa 84,17 persen (20 lokasi) telah mengalami kerusakan dan hanya satu lokasi 3,7 persen terumbu karangnya masih sangat baik. Kondisi umum terumbu karang di beberapa kawasan di menyebabkan ikan mati dan dapat digunakan untuk membius ikan-ikan yang berada diselasela karang yang tidak mungkin ditangkap dengan menggunakan jaring/pancing. Walaupun racun yang digunakan tidak menyebabkan ikan mati, tetapi racun tersebut dapat membunuh terumbu karang, sehingga penggunaan racun untuk menangkap ikan termasuk perbuatan yang merusak terumbu karang.

Tabel 8. Rata-Rata Distribusi Liputan Karang (\%) di Beberapa Pulau di Sumatera Barat Sampai Tahun 2004-2009

\begin{tabular}{lrrrrrrr}
\hline \multicolumn{1}{c}{ Lokasi } & $\begin{array}{c}\text { HCA } \\
\mathbf{( \% )}\end{array}$ & $\begin{array}{c}\text { HCNA } \\
\mathbf{( \% )}\end{array}$ & $\begin{array}{c}\text { DC } \\
\mathbf{( \% )}\end{array}$ & $\begin{array}{c}\text { ALGA } \\
\mathbf{( \% )}\end{array}$ & \multicolumn{1}{c}{$\begin{array}{c}\text { OF } \\
\mathbf{( \% )}\end{array}$} & $\begin{array}{c}\text { Abiotik } \\
\mathbf{( \% )}\end{array}$ & $\begin{array}{c}\text { Total PC } \\
\mathbf{( \% )}\end{array}$ \\
\hline Sikuai & 3,57 & 14,22 & 0,00 & 64,18 & 4,62 & 0,40 & 19,02 \\
Sirandah & 0,6 & 11,433 & 0,00 & 54,76 & 8,17 & 0,00 & 11,09 \\
Sinyaro & 0,54 & 20,27 & 0,00 & 54,75 & 11,8833 & 0,00 & 23,37 \\
Pasumpahan & 1,02 & 17,65 & 0,00 & 46,90 & 10,19 & 0,0 & 17,87 \\
\hline
\end{tabular}


(3) Bom. Penggunaan bom atau bahan peledak untuk menangkap ikan juga melanggar hukum. Cara-cara seperti ini digunakan orang-orang yang serakah, ingin mendapatkan hasil sebanyak-banyaknya dalam waktu yang singkat. Akibatnya banyak organisme yang akan mati, tidak hanya ikan, terumbu karang juga akan hancur kena ledakan.

(4) Pariwisata Bahari. Pariwisata bahari seperti menyelam, memancing, berlayar, jetski dan lain sebagainya dapat menjadikan penyebab kerusakan terumbu karang jika tidak dilaksanakan dengan memperhatikan pelestarian lingkungan. Para penyelam pemula yang baru dapat menyelam sehingga kemampuan menyelamnya kurang baik, dapat menginjak dan mamatahkan terumbu karang jika ia langsung menyelam pada tempat yang ada terumbu karangnya. Kapal-kapal yang mengantar para penyelam atau turis memancing ikan juga membuang jangkar secara sembarangan disekitar terumbu karang juga dapat menyebabkan kehancuran terumbu karang.

Upaya Pelestarian Terumbu Karang. Pemanfaatan ekosistem pesisir pantai dan laut termasuk ekosistem terumbu karang adalah untuk memenuhi kebutuhan manusia yang kadangkala bertentangan dengan beberapa kepentingan yang lainnya. Karena gangguan manusia terhadap sistem ekologi kawasan pesisir pantai dan laut maka harus disusun dengan baik agar manfaat pengelolaan laut dan pesisir yang didapatkan dari ekosistem dapat menguntungkan manusia dengan tetap menjaga keaslian ekosistemnya. Sedangkan pelestarian terumbu karang melalui aturan bertujuan untuk melindungi kelangsungan proses alamiah dalam sistem ekologi sehingga fungsi dan manfaatnya dapat dirasakan secara berkelanjutan. Beberapa kegiatan yang dapat mendukung pelestarian terumbu karang seperti:

(1) Menyediakan fasilitas umum untuk memudahkan para pengunjung mendatangi pulaupulau seperti pembuatan pangkalan kapal, mooring bouy, air minum, pembuangan sampah, dan syarat-syarat khusus kapal yang mesti digunakan; (2) Kegiatan ecoturism di kawasan terumbu karang sudah semakin populer seperti "sport fishing" dalam keadaan terkontrol, bermain perahu layar, snorkling dan scuba diving, berenang dan aktivitas lainnya. Perlu pembagian kawasan kegiatan; (3) Melakukan pengawasan terhadap para pengunjung yang datang dengan aktivitas-aktivitas yang dapat mencemarkan alam dan lingkungan serta kebersihan air dan kebersihan perairan di kedua pulau dan harus dilakukan secara berkelanjutan; (4) Direncanakan pembangunan dan pengembangan pulau yang terprogram dan berkelanjutan dan penyediaan fasilitas untuk dipublikasikan kepada pengunjung pulau (Damanhuri, 2003).

\section{SIMPULAN}

Dalam pengelolaan sumber daya dan strategi pembangunan pada bidang kelautan dan perikanan, sangatlah penting untuk dibuat kebijakan yang menyeluruh setelah pasca gempa di Sumatera Barat, sehingga "Ocean policy" jelas dan yang lebih terpenting adalah bagaimana nelayan dapat kembali lagi untuk melaut setelah pasca gempa, dapat meningkatkan kesejahteraan dan lebih diberdayakan di era desentralisasi. Karena, semangat pengelolaan sumber daya kelautan adalah semangat otonomi yang meletakkan daerah sebagai sumbu utama lokomotif pelaksanaannya. Dalam konteks ini, daerah memiliki kewenangan untuk mengatur dan mengelola sumberdaya kelautannya dengan tujuan utama tentunya pada kesejahteraan daerah dan masyarakat yang ada di dalamnya.

\section{DAFTAR PUSTAKA}

Dahuri, R. 2001. Otonomi pengelolaan sumberdaya laut dalam. Suara Pembaharuan 23 April.

Damanhuri. H., 2003. Terumbu Karang Kita. Jurnal Mangrove dan Pesisir Vol. III No. 2. Pusat Kajian Mangrove dan Kawasan Pesisir Universitas Bung Hatta, hal: 28-33.

Dinas Kelautan dan Perikanan (DKP). 19992004. Statistik Perikanan. Sumatera Barat: DKP.

Dinas Kelautan dan Perikanan (DKP). 2009. Profil Perikanan Tangkap Provinsi Sumatera Barat.

Harian Singgalang. 1998, 8 Pebruari. Perairan 
Sumatera Barat Tercemar Phytoplankton. Hlm. 1.

Kamal, E dan J. S. Bujang. 1999. Kontribusi dan Pemanfaatan Hutan Mangrove Bagi Perikanan. Jurnal Garing Volume 8 No. 2 Oktober 1999. Hlm. 57-62.

Kamal, E. 2002. Pemberdayaan Masyarakat Nelayan dan Pendekatan Budaya. PKMKP, Universitas Bung Hatta.

Kamal, E. 2003. Membangun Perikanan Berbasis Kerakyatan. PKMKP, Universitas Bung Hatta.

Kamal. E., J. S. Bujang, M. Rahman dan S. Othman. 1998. Kondisi dan Kebijakan Hutan Mangrove di Sumatera Barat. Majalah Il- miah Wawasan IPTEKNI Tahun V No. 2. Hlm. 73-83.

Kamal. E., L. Hermalena, R. Tamin, dan Suardi ML. 2003. Mangrove Sumatera Barat. Padang: Pusat Kajian Mangrove dan Kawasan Pesisir Universitas Bung Hatta.

Kamaluddin, L.M. 2000. Desentralisasi Pengelolaan Sumberdaya Pesisir Lautan. Makasar: Konferensi Sumberdaya pesisir tgl. 15-17 Mei.

Liley, G. 1997. Terancamnya Terumbu Karang Indonesia. Tanah Air: Vol. 3, Hlm. 22-23.

Usher, G. 1997. Coral Reef, Conservation Indonesia: April-June, page: 23-27. 